\title{
ACUTE EFFECTS OF COLD WATER IMMERSION ON CARDIOVASCULAR AND AUTONOMIC RESPONSES
}

\author{
Gabriel Costa e Silva ${ }^{1,2}$, Rodrigo Rodrigues da Conceição ${ }^{3}$, Carlos V. \\ Herdy $^{4}$, Anderson Silveira ${ }^{5}$, Fabrízio Di Masi ${ }^{5,6}$ \\ ${ }^{1}$ Doctoral Program in Health Sciences, ABC Medical School, ABC Foundation, Brazil. \\ ${ }^{2}$ Group of Studies in Sciences of the Human Movement, Pedro II College, Brazil. \\ ${ }^{3}$ Doctoral Program in Clinical Endocrinology, Federal University of São Paulo, Brazil. \\ ${ }^{4}$ Department of Physical Education, Estácio de Sá University, Rio de Janeiro, Brazil. \\ ${ }^{5}$ Laboratory of Physiology and Human Performance, Federal Rural University of Rio de Janeiro, Brazil. \\ ${ }^{6}$ Human Motricity Bioscience Laboratory, LABIMH, Federal University of State of Rio de Janeiro, Brazil.
}

OPEN ACCES

Correspondencia: Fabrízio Di Masi

Human Motricity Bioscience Laboratory LABIMH,

Federal University of State of Rio de Janeiro (Brazil) fabdimasi@gmail.com

Funciones de los autores: Todos los autores trabajaron en la ejecución del proyecto (concepción recolección estadisti revisión), bajo la orientación del profesor Fabrizio Di Masi

Recibido: 5/04/2018 Aceptado: 9/11/2018 Publicado: 31/01/2019

Citación:

Silva, G. C., Conceição, R. R., Herdy, C. V.,

Silveira, A. 1 Acute effects of cold water immersion on cardiovascular and autonomic responses. RIAA. Revista de Investigación en Actividades Acuáticas, 3(5) 8-13. https://doi.org/10.21134/riaa.v3i5.1543

@creative

(c) 10 (1)(2)

Creative Commons License sta obra está bajo una licencia d Creative Commons ReconocimientoNoComercial-Compartir-Igua 4.0 Internacional
Background: Immersion has been used for many years for therapeutic purposes, but more recently the cardiovascular and authonomic effects appear as an important change in the organism during immersion in the aquatic environment. Objectives: The aim of this study was to investigate the acute effect of water immersion $\left(22.6^{\circ} \mathrm{C}\right)$ on heart rate, heart rate variability, body temperature, oxygen saturation, diastolic blood pressure and systolic blood pressure in young apparently healthy men. Method: Nine apparently healthy males were randomly allocated to an experimental situation (SE) and one control (SC). The SE subjects had the variables measured after the 10 minutes immersion. The subject of the SC remained 10 minutes at rest in the terrestrial environment. After $48 \mathrm{~h}$, the procedures were performed the reverse manner to perform balanced input. Results: After 10 minutes of immersion in water was observed reduction in the values of heart rate, significant increases on the RR intervals. The values of RMSSD (ms) increased after immersion, as shown pNN50 (\%) and HF index increased $(p=0.009)$. The ratio (LF / HF) decreased after immersion. Significant differences when comparing the SBP were observed.

Conclusions: Thus, is concluded that the immersion in water $(22.60 \mathrm{C})$ increases vagal activity and reduces modulation of the sympathetic branch of the autonomic nervous system.

Key words: Heart rate variability, water activities, autonomic nervous system.

Titulo: Efecto agudo de la inmersión en agua fría en las respuestas cardiovasculares y autonómicas.

Antecedentes: La inmersión viene siendo usada desde hace muchos años con fines terapéuticos, pero más recientemente los efectos cardiovasculares y autonómicos surgen cómo un cambio importante en el organismo durante la inmersión en el ambiente acuático.

Objetivos: El objetivo de esta investigación fue investigar el efecto agudo de la inmersión en agua $\left(22.6^{\circ} \mathrm{C}\right)$ sobre la frecuencia cardiaca, la variabilidad de la frecuencia cardíaca, la temperatura corporal, la saturación de oxígeno, la presión arterial diastólica y la presión arterial sistólica en hombres jóvenes aparentemente saludable.

Método: Nueve hombres aparentemente sanos fueron asignados al azar en una situación experimental (SE) y otro control (SC). Los participantes del SE se les midió después de los 10 minutos de inmersión. Los participantes del SC permanecieron 10 minutos en reposo en el ambiente terrestre. Después de $48 \mathrm{~h}$, los procedimientos se realizaron de manera inversa para realizar la entrada balanceada.

Resultados: Después de 10 minutos de inmersión en agua se observó reducción en los valores de la frecuencia cardíaca, aumentos significativos en los intervalos RR. Los valores de RMSSD (ms) aumentaron después de la inmersión, como demuestra el aumento del pNN50 (\%) y del índice HF. La relación (LF/HF) disminuyó después de la inmersión. Se observaron diferencias significativas cuando se comparó la PAS

Conclusiones: Se concluye que la inmersión en agua (22.6드) aumenta la actividad vagal y reduce la modulación de la rama simpática del sistema nervioso autónomo.

Palabras clave: variabilidad de la frecuencia cardíaca, actividades acuáticas, sistema nervioso autónomo

Titulo: Efeito agudo da imersão em água fria na respostas cardiovasculares e autonômicas

Contexto: A imersão vem sendo usada há muitos anos com finalidades terapêuticas, entretanto mais recentemente os efeitos cardiovasculares e autônomicos surgem como uma alteração importante no organismo durante a imersão no ambiente aquático Objetivos: $O$ objetivo deste estudo foi investigar o efeito agudo da imersão em água $\left(22,6^{\circ} \mathrm{C}\right)$ sobre a frequência cardíaca, variabilidade da frequência cardíaca, temperatura corporal, saturação de oxigênio, pressão arterial diastólica e pressão arterial sistólica em homens jovens aparentemente saudáveis.

Método: Nove homens aparentemente saudáveis foram alocados aleatoriamente em uma situação experimental (SE) e um controle (SC). Os participantes do SE tiveram as variáveis medidas após os 10 minutos de imersão. Os participantes do SC permaneceram 10 minutos em repouso no ambiente terrestre. Após $48 \mathrm{~h}$, os procedimentos foram realizados de maneira reversa para realizar a entrada balanceada.

Resultados: Após 10 minutos de imersão em água foi observada redução nos valores da frequência cardíaca, aumentos significativos nos intervalos RR. Os valores de RMSSD (ms) aumentaram após a imersão, conforme demonstrado pelo aumento do pNN50 (\%) e do índice HF. A relação (LF / HF) diminuiu após a imersão. Diferenças significativas quando comparadas a PAS foram observadas. Conclusões: Conclui-se que a imersão em água $(22.6 \circ \mathrm{C})$ aumenta a atividade vagal e reduz a modulação do ramo simpático do sistema nervoso autônomo.

Palavras-chave: variabidlidade da frequência cardiaca, atividades aquáticas, sistema nervosa autônomo. 
Introduction

Activities involving the aquatic environment are being recommended to reduce pain (Bender et al., 2005; Kihlstrand et al., 1999), cardiac (Cider, 2006) and orthopedic rehabilitation (Bartels et al., 2007), as well as improvement in the body composition (Latorre et al., 2013), and health performance parameters (Tsourlou et al., 2006; GUSI et al., 2006; Taunton et al., 1996). According to Fujishima and Shimizu (2003), due the water physical properties, immersion might be able to modulate physiological responses in humans. Thus, the combination of these properties (hydrostatic pressure, thermal effects of water, reducing the hydrostatic weight, and others) can promote high blood accumulation in the body central region, thereby causing cardiovascular changes (Kruel, 2000; Brasil \& Di Masi, 2006).

Florian et al. (2013) found in young adults who underwent three protocols of physiological stress, different modulations in autonomic activation/ deactivation, heart rate variability (HR), systolic blood pressure (SBP) and stroke volume after 6 hours of full body immersion in aquatic environment. Furthermore, it was already described that the water immersion promotes changes in the chemical regulators levels, the intrapleural pressure, $\mathrm{CO}_{2}$ pressure and arterial $\mathrm{pH}$ (Anderson et al., 2002; Kinoshita et al., 2006), and modulates autonomic responses such as vasoconstriction, decreased heart rate (HR), decreased cardiac output, and increased stroke volume (Aanderson et al., 2000; Graef et al, 2005).

In another hand, the analysis of heart rate variability (HRV), which is commonly used as a non-invasive method for the neural control of the heart (Kingsley et al., 2005; Numan et al., 2009), have been widely applied in science to autonomic control of heart rate in exercise and rest. In focus, several studies reported an increase in parasympathetic activity after analyzing the physiological responses to immersion of the face (face immersion) at different temperatures (Perine et al., 1998 Mourot et al., 2008; Miwa et al., 1997; Al Hadda et al., 2010), such responses are justified in so far that the immersion of the face probably generates reflexive response involving the trigeminal brain vagal pathways (Kinoshita et al., 2006). However, our group observed that there is a gap in the literature linking hemodynamic variables and whole-body water immersion that is quite common in sports and therapeutic practices (Kamioka et al., 2010; Kruel, 2000; Brasil \& Di Masi, 2006). Nevertheless, the aim of this study was to investigate the acute effect of whole-body water environment immersion $\left(22.6^{\circ} \mathrm{C}\right)$ on $\mathrm{HR}, \mathrm{HRV}$, body temperature, oxygen saturation (SO), diastolic blood pressure (DBP) and SBP in young apparently healthy men.

\section{Method}

\section{Subjects}

Nine $(n=9)$ apparently healthy males $(21.4 \pm 2.3$ years, $174.8 \pm 9.1 \mathrm{~cm}$ and $72.5 \pm 10.93 \mathrm{~kg}$ ) were selected for inclusion in the study. The inclusion criteria were: Being physically active; to not perform any type of physical exercise during the day of the experiment, not to be under the effect of any drug or alcohol, do not drink caffeine for at least $24 \mathrm{~h}$ before the experiment and show no medical condition that may adversely affect the results of the study. All participants read and signed an Informed Consent Form containing information about the possible risks and benefits to participation in the experimental procedures. The study was conducted in accordance with the recommendations of Resolution 466/2012 of the National Health Council. Study was approved by the Ethics Committee in Research of the Federal Rural University of Rio de Janeiro (Protocol 003354/2012-81).

Variables assessment
Anthropometric variables used in the present study, body weight was measured by digital scale (Plenna, 0.1lbs, USA) and height by stadiometer (Sanny, $0.1 \mathrm{~cm}$, Brazil). The cardiac analysis was obtained by a hear rate monitor (Polar, RS 800 CX, USA) validated in previous studies (KINGSLEY et al., 2005; NUNAN et al., 2009). The electrode was previously moistened and positioned in the direction of the sternum, at the level of the xiphoid process. After obtaining the data, they were transferred to a computer by Polar ${ }^{\circledR}$ infrared interface, processed by Polar Precision Performance ${ }^{\circledR}$ software (Polar Precision Performance 4.03 software, Polar Electro OY, Finland), and stored in the computer for analysis. The data were then exported to the Kubios HRV (Kubios HRV Analysis Version 3.0 beta, Finland) program, where were then filtered according to the recommendations of the Task Force of Spectral Analysis (Task Force of the European Society of Cardiology and the North American Society of Pacing and Electrophysiology, 1996). The spectral analysis in the frequency domain was performed by the Fourier transform algorithm.

In the evaluation obtaining the values of SO, a pulse oximeter (Ohmeda 3740, USA) was used. The probe was fixed to the distal phalanx of the index finger of your dominant hand and sustained by a flat surface for stabilization. The determination of values of blood pressure, we used a Aneroid Sphygmomanometer (Tycos, USA) and stethoscope (II Litman, USA). The fastening of the cuff on the arm occurred approximately 2.5 $\mathrm{cm}$ away from the lower end and the antecubital fossa. The measures were made always at the left arm, positioned on a flat surface at shoulder height. We used the I and IV Korotkoff sounds as systolic and diastolic values respectively. The measurements were performed by the same examiner with experience in the use of auscultation (PERLOFF et al., 1993).

\section{Procedures}

Procedure for collection of data occurred between 8:00 at 9:00 a.m in the Laboratory of Physiology and Human Performance at the Federal Rural University of Rio de Janeiro (LFDH / UFRRJ), on non-consecutive days with the total of three visits:

1a visit. On the first visit, after signing the consent form, the subjects underwent medical interview, anthropometric measurements and recorded the values of $\mathrm{HR}, \mathrm{SBP}, \mathrm{DBP}, \mathrm{SO}$ and body temperature.

$2^{a}$ visit. In this time the subjects were randomly allocated to an experimental situation (SE) and one control (SC). The SE subjects, after 10 minutes being at rest in the terrestrial environment, moved slowly and dipped in the pool $(12.5 \times 6 \times 1.5 \mathrm{~m})$ to 22.6 ․ C. Thereafter HR, HRV, body temperature, SO, DBP and SBP was measured. However, the pressure values and SO were measured only immediately after 10 minutes of immersion. The subject of the SC remained 10 minutes at rest in the terrestrial environment, following the same conditions of the subjects of the SE. Then continued in the same position, even in terrestrial environment, for another 10 minutes and immediately after the end of 10 minutes was measured the same variables.

3a visit. In this visit procedures were performed in the reverse manner. Subjects who initially underwent SE, underwent SC this time. In contrast, the reverse procedure was applied to the subjects SC to perform balanced input.

\section{Statistical Analysis}

The Shapiro-Wilk test was used to verify the normality between the data involved in the study. In this sense, the present study used only parametric analysis. The non-paired t-tests were performed to compare the values of HR, RR interval and HRV indexes. A two-way ANOVA was performed for the comparison of body temperature, DBP, SBP and SO. The Bonferroni post hoc test was then performed. Statistical analyzes 
were conducted from the statistical software package GraphPad Prism 5.0. A significance level of $p<0.05$ was used for all analyzes.

\section{Results}

Table 1 shows the climatic conditions for the different study days. In this sense, after 10 minutes of immersion in water a significant ( $p<$ $0.0001)$ reduction in the values of $\mathrm{HR}(\mathrm{bpm})$ was observed, as shown in Figure 1. Significant differences $(p<0.0001)$ were observed when comparing the intervals RR after 10 minutes of immersion, as shown in Figure 2. When comparing the values of RMSSD (ms) between the aquatic environment and dryland, significant differences were observed ( $p=0.007$ ), as shown in Figure 3. When comparing the values of pNN50 (\%) between the aquatic environment and dryland, significant differences were observed ( $p=0.002$ ), as shown in figure 4 . When comparing the use of high frequency bands (HF) between the aquatic environment and dryland, significant differences ( $p=0.009$ ) were observed, as shown in Figure 5. When comparing the usage ratio of bands of high and low frequency (LF/HF) between the aquatic environment and dryland, significant differences $(p=0.01)$ were also found, as shown in Figure 6.

Table 1. Different days climatic conditions.

\begin{tabular}{lcccc}
\hline $\begin{array}{l}\text { Environment } \\
\text { conditions }\end{array}$ & $1^{\mathrm{a}}$ visit & $\begin{array}{c}2^{\mathrm{a}} \\
\text { visit }\end{array}$ & $3^{\mathrm{a}}$ visit & Mean $\pm \mathrm{SD}$ \\
\hline $\mathrm{LT}\left({ }^{\circ} \mathrm{C}\right)$ & 22.6 & 34.5 & 25.0 & $27.3 \pm 1.5$ \\
$\mathrm{WT}\left({ }^{\circ} \mathrm{C}\right)$ & 22.5 & 24.1 & 21.1 & $22.6 \pm 6.2$ \\
$\mathrm{UR}(\%)$ & 47.0 & 34.0 & 52.0 & $44.3 \pm 9.2$ \\
\hline
\end{tabular}

Note: SD = Standart Devitation; LT = Land temperature; $\mathrm{WA}=$ water temperature; $\mathrm{UR}=$ air relative humidity.

Figure 1. Heart rate comparison between land and water environment.

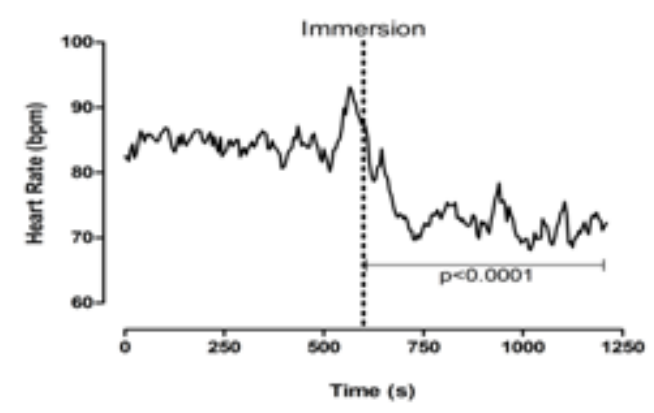

Figure 2. RR interval comparison between land and water environment.

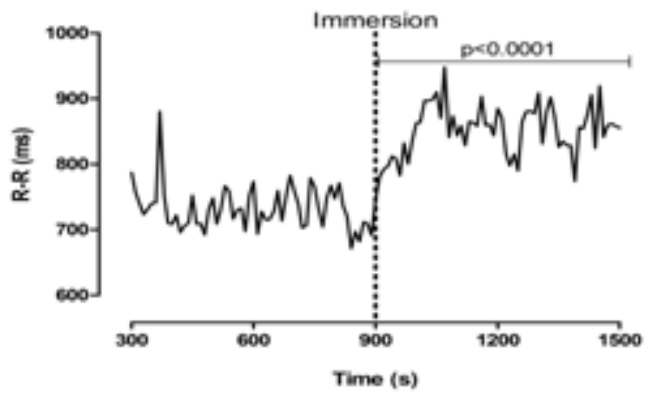

Figure 3. RMSSD (ms) comparison between land and water environment.

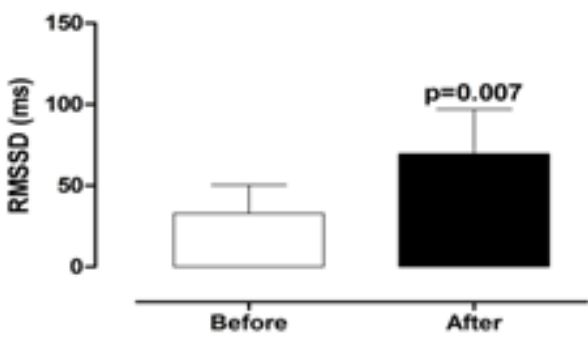

Figure 4. pNN50 (\%) comparison between land and water environment.

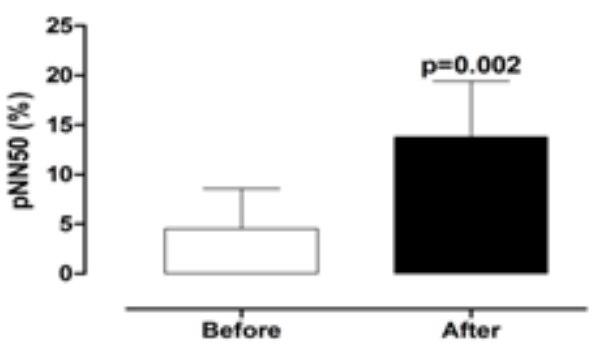

Figure 5. High frequency bands comparison between land and water environment.

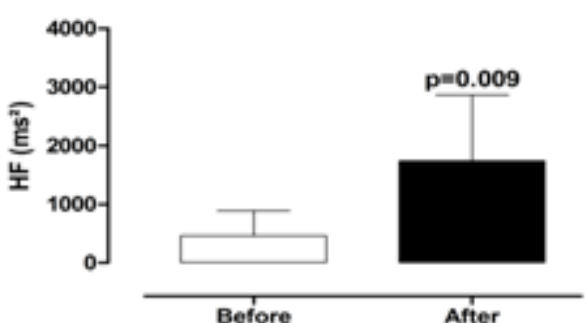

Figure 6. High frequency and low frequency ratio (LF/HF) comparison between land and water environment.

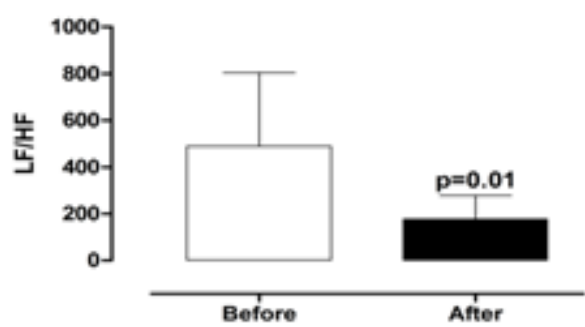

No significant differences $(p>0.05)$ were observed when comparing the values of body temperature between the aquatic environment and dryland. No significant differences $(p>0.05)$ were observed when comparing the values of OS between the aquatic environment and dryland. No significant differences $(p>0.05)$ were observed in the comparison of DBP between the liquid environment and land. However, significant differences $(p>0.05$ ) when comparing the SBP between the liquid environment and ground were observed, as shown in Figure 7. 
Figure 7. Diastolic blood pressure, Systolic blood pressure and oxygen saturation comparison between land and water environment. * Represents significant difference $(p<0.05)$.
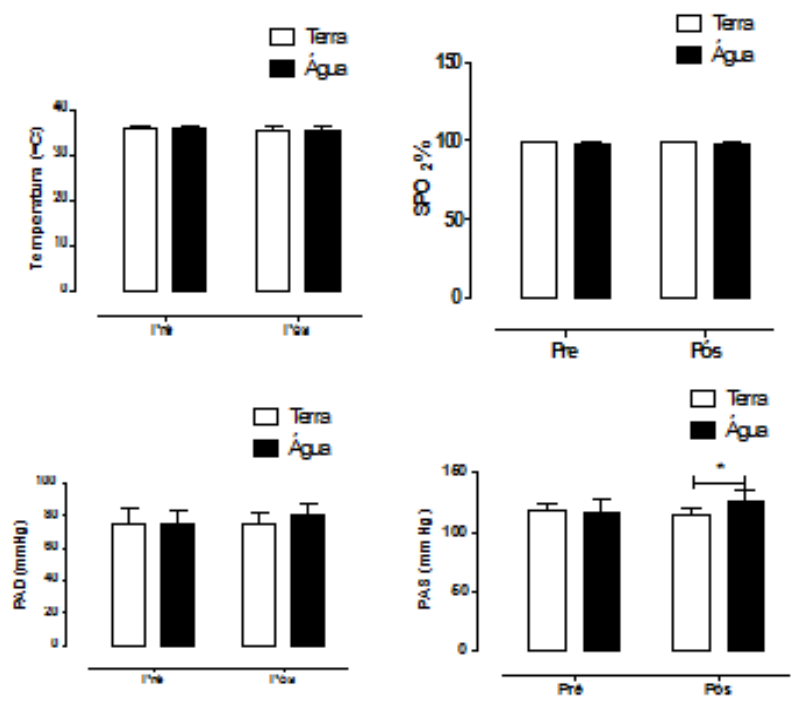

\section{Discussion}

The heart rate variability (HRV) is an accurate and non-invasive method to assess autonomic modulation in the time domain or frequency. Therefore, the proposal of our study was to compare and evaluate the modulation of autonomic and physiological variables between the land and water environment in a situation close to that observed in practical daily life of certain therapeutic and sports activities. Our best results indicated that the immersion in water $\left(22.6^{\circ} \mathrm{C}\right)$ increases vagal activity and reduces modulation of the sympathetic branch of the autonomic nervous system.

Starting with this technique the HR is recorded in a given space of time, which is specifically measured the distance in unit time between RR peaks corresponding to the selected time. However, Eckberg et al. (1997) point out that RR intervals are not clear indicators for the behavior of blood pressure variables. Already HRV in the frequency domain, also known as spectral analysis, occurs from the same measurement of RR intervals, which will be applied a set of mathematical equations, in order to transform this event repeated spectra and thus determine the frequencies at which these spectra happen, and is already well described in the literature that these frequency bands are directly related to sympathetic and vagal modulation.

\section{Accordingly, it was observed that after 10 minutes} of immersion a significant decrease in HR (Figure 1), accompanied by significant increases in $R R$ intervals (Figure 2) happened. In addition, when the analysis continues in the time domain, the results showed significantly higher values RMSSD compared to dryland (Figure 3 ), as well as the values of pNN50 (\%) (Figure 4). According to some related immersion of the face (face immersion) studies observed similar responses, due to increased blood accumulation in the trunk (MIWA et al., 1997), and Perine et al. (1998) founnd increased stroke volume and cardiac output, and consequent decrease in HR.According to spectral analysis, it was observed that a significant increase in HF after 10 minutes immersion (Figure 5). However, to evaluate the sympatho-vagal autonomic balance through ratio $\mathrm{LF} / \mathrm{HF}$, a significantly reduction was observed during immersion, demonstrating a greater vagal participation and confirming the results found for the HF (Figure 6). Therefore, regarding the cardiac activity, it can be inferred that a 10 minutes immersion in cold water is able to increase the modulation of the parasympathetic branch of the autonomic nervous system and can interfere in the sympathetic tone in order to reduce the modulation thereof. It can also be seen that these phenomena begin to occur immediately upon entry into the water, as may be seen in Figures 1 and 2.

Thus, the decrease in HR was found justified in a greater vagal modulation and lower sympathetic modulation was observed during immersion (Al Haddad et al., 2010). Several studies also found that immersion of the whole body in water is an effective method to significantly reduce the HR (Conti et al., 2008; Svedenhag \& Segen, 1992; Town \& Bradley, 1991; Smárek et al., 2000; Kruel, 1994). Additionally, it is believed that the accumulation of blood in the central part of the body caused by the hydrostatic pressure added to the thrust contributed to this effect (Arborrelius et al., 1972).

However, no significant differences in body temperature (Figure 7) were found. Thus, it is suggested that the increase in the vagal tone generated by water immersion $\left(22.6^{\circ} \mathrm{C}\right)$ even at relatively low temperature, does not significantly interfere in the thermoregulatory responses. Mourot et al. (2008) found that immersion in thermoneutral water $\left(34-35^{\circ} \mathrm{C}\right)$ decreases sympathetic activity and arterial tone in 12 healthy subjects, realizing also that the sympathetic-vagal mechanism appears to be quite complex when it comes to thermal body changes, given that the authors found an inverse relationship immersion in water at $26-27^{\circ} \mathrm{C}$.

The contribution of peripheral oxygen is especially influenced by vagal action. The breath into the water is often influenced by increasing hydrostatic pressure, which increases the water pressure on the chest wall, which can cause an increase in the work of breathing (RAY et al., 2008). In contrast, the present experiment showed that after 10 minutes of immersion, the responses were not significantly different from those obtained in the dryland. As Lindholm et al. (2006), changes in alveolar gaseous composition does not seem to be overwhelming the first 10 minutes of immersion. Therefore, without ignoring changes in autonomic nervous system function and physiological changes resulting from the action of the physical properties of water, perhaps influenced by the short period of immersion and the situation of absolute rest of the subjects in the present study, the responses were similar in SO analyzed both ways (land and water). These results suggest that both sympathetic vasomotor and cardiac activities are suppressed and the parasympathetic activity (vagal) during immersion is enhanced.

The hemodynamic responses can be modulated by both the autonomic system as for phenomenon that is unrelated neurophysiological responses. Accordingly, significant increase in SBP was observed after 10 minutes of immersion. The hemodynamic responses can be modulated by both the autonomic system as for phenomenon that are unrelated neurophysiological responses. Accordingly, significant increase in SBP was observed after 10 minutes of immersion. Then, as the main explanation for this response should be noted that the cold water seems to provide a peripheral vasoconstriction and increase the compression of the vessels by hydrostatic pressure tending to increase the SBP, and this process seems to have not suffered any interference 
sympathetic modulation in blood vessels. Di Masi et al. (2006) found similar responses with respect to peripheral vasoconstriction during immersion.

Previous studies suggest that face immersion reduce HR and increase parasympathetic activity of the autonomic nervous system (Perine et al., 1998; Kinoshita et al., 2006; Mourot et al., 2008; Miwa et al., 1997; Al Haddad et al., 2010). In such cases, with the compression of the trigeminal nerve, the vagal would be responsible for these responses (diving reflex). Thus, immersion in water, even to the height of the xiphoid process, promotes acute neurophysiological changes close to those observed after immersion of the face. Buchheit et al. (2008) after submitting 10 male cyclists to supramaximal efforts in cycling on land, compared the effects of 5-minute immersion in cold water $\left(14^{\circ} \mathrm{C}\right)$ while recovery in terrestrial environment. The authors found that immersion in cold water may be able to accelerate parasympathetic reactivation after exercise. The same effect was found in the study of Al Hadaad et al. (2010) which compared the effects of immersion of the face after Wingate test. Corroborating our data at rest, it seems that the autonomic changes after physical exercises, aquatic immersion neuromodulator can exert the same effect on vagal activity compared to immersion at rest.

Although the present findings are promising, some limitations may be considered important and deserve attention and may have influenced certain level of analysis of the fine results of this study. In this context, even with proper care, blood pressure and the SO were measured by indirect methods, as there was no control of biochemical markers that would certainly facilitate the interpretation of results. Moreover, contrary to HR data and HRV recorded during the whole time, the values of body temperature, SBP, SBP and SO were only measured before and after the experimental situations on land and water. However, studies with methodological designs that address these limitations in humans involve complex factors, as they may become invasive and laborious.

\section{Conclusion}

Based on the the present results it is concluded that the immersion in water $\left(22.6^{\circ} \mathrm{C}\right)$ increases vagal activity and reduces modulation of the sympathetic branch of the autonomic nervous system. In this sense, the protocol of immersion in water adopted, despite statistically elevate SBP, significantly reduces $\mathrm{HR}$ and does not alter significantly the body temperature, SO and DBP.

Thus, the experimental protocol used in this study does not allow inferences about the autonomic nervous activity during immersion at other temperatures. Moreover new experiments are suggested aiming at managing different ambient and water temperatures to facilitate understanding of certain context factors, as the example of water temperature and hydrostatic pressure effects.

\section{Contribution and practical implications}

The increase of the heart rate variability during immersion can be considered an antiarrhythmogenic response, this technique can be applied in the future to specific populations.

\section{Acknowledgment}

To the Physical Education and Sports Department of the Federal Rural University of Rio de Janeiro.

\section{References}

Al Haddad, H., Laursen, P. B., Ahmaidi, S., \& Buchheit, M. (2010). Influence of cold water face immersion on post-exercise parasympathetic reactivation. European Journal of Applied Physiology, 108(3), 599-606. https://doi.org/10.1007/s00421-0091253-9

Andersson, J. P. A., Linér, M. H., Rünow, E., \& Schagatay, E. K. A. (2002). Diving response and arterial oxygen saturation during apnea and exercise in breath-hold divers. Journal of Applied Physiology, 93(3), 882-886. https://doi.org/10.1152/japplphysiol.00863.2001

Andersson, J., Schagatay, E., Gislén, A., \& Holm, B. (2000).

Cardiovascular responses to cold-water immersions of the forearm and face, and their relationship to apnoea. European Journal of Applied Physiology, 83(6), 566-572. https://doi.org/10.1007/s004210000317

Arborelius, M., Ballidin, U. I., Lilja, B., \& Lundgren, C. E. (1972). Hemodynamic changes in man during immersion with the head above water. Aerospace Medicine, 43(6), 592-598.

Bartels, E. M., Lund, H., Hagen, K. B., Dagfinrud, H., Christensen, R., \& Danneskiold-Samsøe, B. (2007). Aquatic exercise for the treatment of knee and hip osteoarthritis. In The Cochrane Collaboration (Ed.), Cochrane Database of Systematic Reviews. Chichester, UK: John Wiley \& Sons, Ltd. https://doi.org/10.1002/14651858.CD005523.pub2

Bender, T., Karagalle, Z., Blint, G. P., Gutenbrunner, C., Blint, P. V., \& Sukenik, S. (2005). Hydrotherapy, balneotherapy, and spa treatment in pain management. Rheumatology International, 25(3), 220-224. https://doi.org/10.1007/s00296-004-0487-4

Buchheit, M., Millet, G. P., Parisy, A., Pourchez, S., Laursen, P. B., \& Ahmaidi, S. (2008). Supramaximal Training and Postexercise Parasympathetic Reactivation in Adolescents. Medicine \& Science in Sports \& Exercise, 40(2), 362-371. https://doi.org/10.1249/mss.0b013e31815aa2ee

Cider, Å., Sveälv, B. G., Täng, M. S., Schaufelberger, M., \& Andersson, B. (2006). Immersion in warm water induces improvement in cardiac function in patients with chronic heart failure. European Journal of Heart Failure, 8(3), 308-313. https://doi.org/10.1016/j.ejheart.2005.08.001

Di Masi, F., \& Brasil, R. (2006). A ciência aplicada à hidroginástica. Sprint.

Eckberg, D. L. (1997). Sympathovagal balance: a critical appraisal. Circulation, 96(9), 3224-3232.

Florian, J. P., Simmons, E. E., Chon, K. H., Faes, L., \& Shykoff, B. E. (2013). Cardiovascular and autonomic responses to physiological stressors before and after six hours of water immersion. Journal of Applied Physiology, 115(9), 1275-1289. https://doi.org/10.1152/japplphysiol.00466.2013

Fujishima, K., \& Shimizu, T. (2003). Body temperature, oxygen uptake and heart rate during walking in water and on land at an exercise intensity based on RPE in elderly men. Journal of Physiological Anthropology and Applied Human Science, 22(2), 83-88.

Graef, F. I., \& Kruel, L. F. M. (2006). Freqüência cardíaca e percepção subjetiva do esforço no meio aquático: diferenças em relação ao meio terrestre e aplicações na prescrição do exercício - uma revisão. Revista Brasileira de Medicina do Esporte, 12(4), 221-228. https://doi.org/10.1590/S1517-86922006000400011

Gusi, N., Tomas-Carus, P., Häkkinen, A., Häkkinen, K., \& Ortega-Alonso, A. (2006). Exercise in waist-high warm water decreases pain and improves health-related quality of life and strength in the lower extremities in women with fibromyalgia. Arthritis \& Rheumatism, 55(1), 66-73. https://doi.org/10.1002/art.21718

Kamioka, H., Tsutani, K., Okuizumi, H., Mutoh, Y., Ohta, M., Handa, S., ... Honda, T. (2010). Effectiveness of Aquatic Exercise and Balneotherapy: A Summary of Systematic Reviews Based on Randomized Controlled Trials of Water Immersion Therapies. Journal of Epidemiology, 20(1), 2-12. https://doi.org/10.2188/jea.JE20090030

Kihlstrand, M., Stenman, B., Nilsson, S., \& Axelsson, O. (1999). Watergymnastics reduced the intensity of back/low back pain in pregnant women. Acta Obstetricia Et Gynecologica Scandinavica, 78(3), 180185. 
Kingsley, M., Lewis, M. J., \& Marson, R. E. (2005). Comparison of Polar 810s and an ambulatory ECG system for RR interval measurement during progressive exercise. International Journal of Sports Medicine, 26(1), 39-44. https://doi.org/10.1055/s-2004-817878

Kinoshita, T., Nagata, S., Baba, R., Kohmoto, T., \& Iwagaki, S. (2006). Cold-water face immersion per se elicits cardiac parasympathetic activity. Circulation Journal: Official Journal of the Japanese Circulation Society, 70(6), 773-776.

Kruel, L. F. M. (2001). Alterações fisiológicas e biomecânicas em indivíduos praticando exercícios de hidroginástica dentro e fora d'água. Kinesis, O(0). https://doi.org/10.5902/2316546410373

Latorre, P. Á., Santos, M. A., Heredia-Jiménez, J. M., DelgadoFernández, M., Soto, V. M., Mañas, A., \& Carbonell-Baeza, A. (2013). Effect of a 24-week physical training programme (in water and on land) on pain, functional capacity, body composition and quality of life in women with fibromyalgia. Clinical and Experimental Rheumatology, 31(6 Suppl 79), S72-80.

Lindholm, P., \& Lundgren, C. E. G. (2006). Alveolar gas composition before and after maximal breath-holds in competitive divers. Undersea \& Hyperbaric Medicine: Journal of the Undersea and Hyperbaric Medical Society, Inc, 33(6), 463-467.

Miwa, C., Sugiyama, Y., Mano, T., Iwase, S., \& Matsukawa, T. (1997). Sympatho-vagal responses in humans to thermoneutral head-out water immersion. Aviation, Space, and Environmental Medicine, 68(12), 1109-1114.

Mourot, L., Bouhaddi, M., Gandelin, E., Cappelle, S., Dumoulin, G., Wolf, J.-P., ... Regnard, J. (2008). Cardiovascular autonomic control during short-term thermoneutral and cool head-out immersion. Aviation, Space, and Environmental Medicine, 79(1), 14-20.

Nunan, D., Jakovljevic, D. G., Donovan, G., Hodges, L. D., Sandercock, G. R. H., \& Brodie, D. A. (2008). Levels of agreement for RR intervals and short-term heart rate variability obtained from the Polar S810 and an alternative system. European Journal of Applied Physiology, 103(5), 529-537. https://doi.org/10.1007/s00421-008-0742-6

Perini, R., Milesi, S., Biancardi, L., Pendergast, D. R., \& Veicsteinas, A. (1998). Heart rate variability in exercising humans: effect of water immersion. European Journal of Applied Physiology, 77(4), 326-332. https://doi.org/10.1007/s004210050341

Perloff, D., Grim, C., Flack, J., Frohlich, E. D., Hill, M., McDonald, M., \& Morgenstern, B. Z. (1993). Human blood pressure determination by sphygmomanometry. Circulation, 88(5 Pt 1), 2460-2470.

Ray, A. D., Pendergast, D. R., \& Lundgren, C. E. G. (2008). Respiratory muscle training improves swimming endurance at depth. Undersea \& Hyperbaric Medicine: Journal of the Undersea and Hyperbaric Medical Society, Inc, 35(3), 185-196.

Šrámek, P., Šimečková, M., Janský, L., Šavlíková, J., \& Vybíral, S. (2000). Human physiological responses to immersion into water of different temperatures. European Journal of Applied Physiology, 81(5), 436-442. https://doi.org/10.1007/s004210050065

Svedenhag, J., \& Seger, J. (1992). Running on land and in water: comparative exercise physiology. Medicine and Science in Sports and Exercise, 24(10), 1155-1160.

Takahashi, S., Iwamoto, M., Yoshimura, M., Laskar, M. S., Shirono, S., Fujimura, T., \& Harada, N. (2003). Factors influencing autonomic nervous function during cold-water immersion test in patients with hand-arm vibration syndrome. International Archives of Occupational and Environmental Health, 76(3), 249-252. https://doi.org/10.1007/s00420-002-0409-2

Taunton, J. E., Rhodes, E. C., Wolski, L. A., Donelly, M., Warren, J., Elliot, J., ... Lauridsen, B. (1996). Effect of Land-Based and Water-Based Fitness Programs on the Cardiovascular Fitness, Strength and Flexibility of Women Aged 65-75 Years. Gerontology, 42(4), 204210. https://doi.org/10.1159/000213794

Town, G. P., \& Bradley, S. S. (1991). Maximal metabolic responses of deep and shallow water running in trained runners. Medicine and Science in Sports and Exercise, 23(2), 238-241.
Tsourlou, T., Benik, A., Dipla, K., Zafeiridis, A., \& Kellis, S. (2006). The Effects of a Twenty-Four-Week Aquatic Training Program on Muscular Strength Performance in Healthy Elderly Women. The Journal of Strength and Conditioning Research, 20(4), 811. https://doi.org/10.1519/R-18455.1 